\title{
First Case of Cytokine Release Syndrome after Nivolumab for Gastric Cancer
}

\author{
Hiroyasu Oda Mikiya Ishihara $^{a}$ Yoshihiro Miyaharab

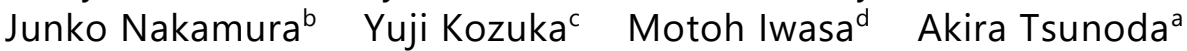 \\ Yoshiki Yamashita $^{a}$ Kanako Saito $^{a}$ Toshiro Mizuno ${ }^{a}$ Hiroshi Shiku $^{b}$ \\ Naoyuki Katayama ${ }^{\mathrm{e}}$ \\ ${ }^{a}$ Department of Medical Oncology, Mie University Hospital, Mie, Japan; ${ }^{b}$ Department of \\ Immuno-Gene Therapy, Mie University Graduate School of Medicine, Mie, Japan; \\ 'Department of Pathology, Mie University Graduate School of Medicine, Mie, Japan; \\ dDepartment of Gastroenterology and Hepatology, Mie University Graduate School of \\ Medicine, Mie, Japan; eDepartment of Hematology and Oncology, Mie University \\ Graduate School of Medicine, Mie, Japan
}

\section{Keywords}

Cytokine release syndrome $\cdot$ Gastric cancer $\cdot$ Nivolumab $\cdot$ Liver injury $\cdot$ TNF- $\alpha$

\begin{abstract}
Introduction: Cytokine release syndrome (CRS) is a potentially life-threatening systemic disease that has been observed after treatment with antibodies and adoptive T cell therapies. In this case, we observed nivolumab-induced CRS in a patient with gastric cancer. Case Presentation: A 43-year-old male with advanced gastric cancer was treated with nivolumab as a thirdline chemotherapy. He had no history of allergies. Eight days after the first administration of nivolumab, fever, tachycardia, appetite loss and increases in liver and biliary enzymes were observed. Computed tomography revealed neither bile duct obstruction nor progression of
\end{abstract}




\section{Case Reports in Oncology}

Case Rep Oncol 2019;12:147-156

DOI: $10.1159 / 000496933$

(c)

(C) 2019 The Author(s). Published by S. Karger AG, Basel www.karger.com/cro

Oda et al.: Cytokine Release Syndrome after Nivolumab

liver metastases but showed that there was edema of the Gleason sheath. Histopathological analysis of the liver revealed cholestatic liver injury with CD8+ T lymphocyte and macrophage infiltration. Neither viral infection nor autoimmune disease was revealed. His symptoms were similar to those of CRS observed after T cell therapy. We diagnosed his disease as nivolumabinduced liver injury and cholangitis accompanied by CRS based on his serum cytokine levels. Discussion/Conclusion: To the best of our knowledge, this is the first report of nivolumabinduced CRS in a patient with gastric cancer.

(C) 2019 The Author(s)

Published by S. Karger AG, Basel

\section{Introduction}

Cytokine release syndrome (CRS) is a potentially life-threatening systemic disease that has been observed after treatment with antibodies such as CD28 antibodies and adoptive T cell therapies such as CD19-specific chimeric antigen receptor (CAR) $\mathrm{T}$ cell therapy. CRS causes various symptoms, such as fever, hypotension, hypoxemia, tachycardia, liver injury and neurological disorders. In the case of CD19-CAR-T-related CRS, treatment with the anti-IL-6 receptor antibody may be an option, but there are no currently available methods of resolving immune checkpoint inhibitor-related CRS [1]. Nivolumab is a well-known immune checkpoint inhibitor that inhibits the binding between PD-1 and its ligands PD-L1 and PD-L2 [2]. There have been some reports of checkpoint inhibitor-related CRS, but not in patients with gastric cancer $[3,4]$.

\section{Case Report/Case Presentation}

A 43-year-old male who had no history or family history of allergies was diagnosed with human epidermal growth factor receptor 2 (HER2)-negative gastric adenocarcinoma. He had been treated with 5 courses of SOX (S-140, 50, or $60 \mathrm{mg}$ according to body-surface area, orally administered twice a day for 14 days with oxaliplatin $100 \mathrm{mg} / \mathrm{m}^{2}$ on day 1 , every 3 weeks) as a first-line chemotherapy and 2 course of paclitaxel + ramucirumab (paclitaxel $80 \mathrm{mg} / \mathrm{m}^{2}$ on days $1,8,15$ with $8 \mathrm{mg} / \mathrm{kg}$ ramucirumab on days 1 and 15, every 4 weeks) as a second-line chemotherapy. However, both treatments failed. He was referred to our department for thirdline chemotherapy. He was $178 \mathrm{~cm}$ tall and weighed $78.3 \mathrm{~kg}$. He had an Eastern Cooperative Oncology Group (ECOG) performance status of 2, body temperature of $36.5^{\circ} \mathrm{C}$, blood pressure of $138 / 92 \mathrm{~mm} \mathrm{Hg}$, pulse rate of 67 beats per minute and $\mathrm{SpO}_{2}$ of $98 \%$ (atmospheric air). Physical examination revealed abdominal pain, back pain and leg oedema. He had taken vonoprazan fumarate, loxoprofensodium, rebamipide, adenine, naldemedine, magnesium oxide, fentanyl patches and a continuous infusion of oxycodone for pain. The baseline laboratory findings are shown in Table 1. A computed tomography (CT) scan showed left adrenal metastasis, peritoneal dissemination and suspected liver metastases. Eight days after the first administration of nivolumab, he developed a high fever $\left(39.0^{\circ} \mathrm{C}\right)$, tachycardia, appetite loss, malaise, and elevated levels of bilirubin, liver enzyme, biliary enzyme and C-reactive protein (CRP) (Table 1, Fig. 1). A CT scan revealed oedema of the Gleason sheath (Fig. 2a). Neither bile duct obstruction nor liver metastasis progression was revealed (Fig. 2b). Histopathological analysis of the 


\section{Case Reports in Oncology}

Case Rep Oncol 2019;12:147-156

DOI: $10.1159 / 000496933$

(c) 2019 The Author(s). Published by S. Karger AG, Base www.karger.com/cro

Oda et al.: Cytokine Release Syndrome after Nivolumab

liver revealed cholestatic liver injury (Fig. 3a). Immunohistochemical examination revealed CD8+ T lymphocyte and macrophage infiltration into the intrahepatic bile duct (Fig. 3b-g). There was no evidence of Epstein-Barr virus infection, cytomegalovirus infection or autoimmune disease (Table 1). Although his blood culture was negative, sulbactam/cefoperazone was started empirically given the possibility of a biliary tract infection. As the levels of bilirubin, biliary enzyme and CRP increased on day 9 (Fig. 2), we started prednisolone (PSL) $80 \mathrm{mg}$ $(1 \mathrm{mg} / \mathrm{kg} /$ day) as a treatment for nivolumab-induced liver injury and cholangitis. His symptoms, including high fever, tachycardia, appetite loss and malaise, without any obvious infection, were similar to the symptoms of CRS that we have observed after TCR-Gene Transduced $\mathrm{T}$ Cell Transfer therapy [5]. The examination of his serum revealed marked elevation of the level of interferon (IFN)- $\gamma$ elevation in the early phase and bimodal elevation of the level of TNF- $\alpha$ (Fig. 1b). His bilirubin level decreased temporarily but subsequently increased (Fig. 1a). On day 22, $1 \mathrm{~g}$ of methyl prednisolone was started for three days. However, his levels of aspartate aminotransferase (AST) and alanine aminotransferase (ALT) were increased. After adding mycophenolate mofetil $2 \mathrm{~g}$ daily to the PSL on day 27, T-bil, his levels of ALT and ALT decreased, but his levels of alkaline phosphatase (ALP) and gamma-glutamyl transferase ( $\gamma$ GTP) continued to increase. Although his bilirubin level was improved after the addition of mycophenolate mofetil, his levels of AST and ALT increased again due to the progression of the liver metastases. He died of gastric cancer on day 105.

\section{Discussion/Conclusion}

Although immune checkpoint blockade is typically described as being well tolerated, it sometimes causes serious immune-related adverse events (irAEs) [6]. In this case, the patient had cholestatic liver injury. Because the examination of the patient's serum revealed marked elevation of the level of IFN- $\gamma$ in the early phase and bimodal elevation of the level of TNF- $\alpha$ (Fig. 1b), we diagnosed his disease as nivolumab-induced liver injury and cholangitis accompanied by CRS.

Non-tumour tissue injury by PD-1 inhibitor-activated T cells is a cause of autoimmunelike disorders. Five cases of nivolumab-induced cholangitis have been reported [7-9]. The nivolumab-induced cholangitis reported by Kawakami and Kashima resulted in bile duct dilation and moderate elevation of the level of bilirubin (peak T-bil 0.7-3.8 mg/dL, bil was not reported by Kashima) [7, 8]. Histopathological analysis of the bile duct revealed infiltration of neutrophils into the mucosa [8]. In contrast, the nivolumab-induced cholangitis reported by Glesomino did not result in bile duct dilation but did cause marked elevation of the level of bilirubin (peak T-bil $10.5 \mathrm{mg} / \mathrm{dL}$ ). Histopathological analysis of the liver revealed the presence of T cells, with a predominance of CD8-positive cells, as part of bile duct aggression and intraductal microabscesses, and mild sinusoidal expansion without fibrosis. Glesomino suggested that there were 2 types of immune-mediated cholangitis, namely, large-duct cholangitis and small-duct cholangitis [9]. In our case, we observed no bile duct dilation and marked elevation of the level of bilirubin (peak T-bil $13.4 \mathrm{mg} / \mathrm{dL}$, peak D-bil $9.9 \mathrm{mg} / \mathrm{dL}$ ), which was similar to small-duct cholangitis. Hypercytokinemia may contribute to small-duct cholangitis. IFN- $\gamma$, TNF- $\alpha$, IL-2 and IL- 6 were assessed by enzyme-linked immunosorbent assay (ELISA) using ELISA kits (Thermo Fisher Scientific Inc., Japan) in this case. It seems that the levels of IFN- $\gamma$, 


\section{Case Reports in Oncology}

IL- 6 and TNF- $\alpha$ were related to the onset of fever and liver injury in the early phase. After the administration of PSL, the levels of IFN- $\gamma$ and IL- 6 decreased immediately, while TNF- $\alpha$ increased. Although mycophenolate mofetil was added to the PSL, it was not able to completely suppress TNF- $\alpha$ (Fig. 1b). These findings suggest that TNF- $\alpha$ might not be secreted by only CD8+ T cells. We know that not only activated T cells secrete IFN- $\gamma$ and TNF- $\alpha$. In our analysis, after PSL administration, the levels of IFN- $\gamma$ and TNF- $\alpha$ decreased immediately, and only the level of TNF- $\alpha$ increased soon thereafter. TNF- $\alpha$ was temporarily suppressed by steroid pulses on days 22-24 (Fig. 1b). These results suggest that nivolumab-activated $\mathrm{T}$ cells are suppressed by PSL and that other cells are less sensitive to steroid-secreted TNF- $\alpha$ after PSL administration. Macrophages are well-known major TNF- $\alpha$-producing cells and are associated with PD$1 /$ PD-L1 signalling. Macrophages might secrete TNF- $\alpha$. Further investigation is needed. The use of an anti-TNF- $\alpha$ antibody at the time of hepatic injury after the administration of an immune checkpoint inhibitor is not recommended to avoid idiosyncratic drug-induced liver injury $[10,11]$. However, in the case of liver injury and cholangitis related to an increase in the level of TNF- $\alpha$, the use of anti-TNF- $\alpha$ antibody might be an option.

HLA-B8, -DR3, and -DRw 52a are thought to be related to the onset of primary sclerosing cholangitis [12], and HLA-DR8 is thought to be related to the onset of primary biliary cirrhosis [13-15]. In this case, the patient's HLAs were HLA-B18, -B51, -DR3, and -DR8. Although Gelsomino stated that HLA-DR11 is characteristic of nivolumab-induced cholangitis, our observations did not support that conclusion [9]. More cases are needed to clarify whether HLA is associated with nivolumab-induced cholangitis.

In our case, the patient received palliative radiotherapy for the cancer pain caused by the left adrenal metastasis (30 Gy in 10 fractions from day 12 to 25). Radiation therapy may increase damage to the radiation field during or after the administration of immune checkpoint inhibitors. However, the first increase in T-bil occurred on day 8 . The mean radiation dose to the liver was $27 \%$. This result suggested that there was little association between liver damage and radiotherapy in this case.

To the best of our knowledge, this is the first report of nivolumab-induced CRS in a patient with gastric cancer. In the case of nivolumab-induced liver injury with TNF- $\alpha$, the use of an anti-TNF- $\alpha$ antibody might be an option. Further investigation is warranted.

\section{Statement of Ethics}

This article does not contain any studies with human participants performed by any of the authors. Written informed consent was obtained from the patient using the hospital default informed consent form.

\section{Disclosure Statement}

The authors have no conflicts of interest to declare. 


\section{Funding Sources}

We do not have any funding source to disclose concerning to this report.

\section{Author Contributions}

H. Oda wrote the initial draft of the manuscript. M. Ishihara contributed to interpretation of data and assisted in the preparation of the manuscript. Y. Miyahara and J. Nakamura contributed to analysis and interpretation of data. M. Iwasa contributed to diagnosis of liver injury. Y. Kozuka contributed to pathological diagnosis. A. Tsunoda, Y. Yamashita, K. Saito and T. Mizuno contributed to clinical treatment. N. Katayama supervised the patient treatment. All other authors critically reviewed the manuscript and approved the final version of the manuscript.

\section{References}

1 Lee DW, Gardner R, Porter DL, Louis CU, Ahmed N, Jensen M, et al. Current concepts in the diagnosis and management of cytokine release syndrome. Blood. 2014 Jul;124(2):188-95.

2 Wang C, Thudium KB, Han M, Wang XT, Huang H, Feingersh D, et al. In vitro characterization of the anti-PD-1 antibody nivolumab, BMS-936558, and in vivo toxicology in non-human primates. Cancer Immunol Res. 2014 Sep;2(9):846-56.

3 Rotz SJ, Leino D, Szabo S, Mangino JL, Turpin BK, Pressey JG. Severe cytokine release syndrome in a patient receiving PD-1-directed therapy. Pediatr Blood Cancer. 2017 Dec;64(12):e26642.

4 Foran AE, Nadel HR, Lee AF, Savage KJ, Deyell RJ. Nivolumab in the Treatment of Refractory Pediatric Hodgkin Lymphoma. J Pediatr Hematol Oncol. 2017 Jul;39(5):e263-6.

5 Kageyama S, Ishihara M, Kitano S, Miyahara Y, Kato H, Mishima H, et al. Tumor responses in a first-in-man trial of a novel affinity-enhanced TCR-Gene Transducted Tcell Transfer Targeting NY-ESO-1 antigen. Blood. 2017;130 suppl 1:841.

6 Michot JM, Bigenwald C, Champiat S, Collins M, Carbonnel F, Postel-Vinay S, et al. Immune-related adverse events with immune checkpoint blockade: a comprehensive review. Eur J Cancer. 2016 Feb;54:139-48.

7 Kawakami H, Tanizaki J, Tanaka K, Haratani K, Hayashi H, Takeda M, et al. Imaging and clinicopathological features of nivolumab-related cholangitis in patients with non-small cell lung cancer. Invest New Drugs. 2017 Aug;35(4):529-36.

8 Kashima J, Okuma Y, Shimizuguchi R, Chiba K. Bile duct obstruction in a patient treated with nivolumab as second-line chemotherapy for advanced non-small-cell lung cancer: a case report. Cancer Immunol Immunother. 2018 Jan;67(1):61-5.

9 Gelsomino F, Vitale G, Ardizzoni A. A case of nivolumab-related cholangitis and literature review: how to look for the right tools for a correct diagnosis of this rare immune-related adverse event. Invest New Drugs. 2018 Feb;36(1):144-6.

10 Brahmer JR, Lacchetti C, Schneider BJ, Atkins MB, Brassil KJ, Caterino JM, et al.; National Comprehensive Cancer Network. Management of Immune-Related Adverse Events in Patients Treated With Immune Checkpoint Inhibitor Therapy: American Society of Clinical Oncology Clinical Practice Guideline. J Clin Oncol. 2018 Jun;36(17):1714-68.

11 Yamashita YI, Imai K, Mima K, Nakagawa S, Hashimoto D, Chikamoto A, et al. Idiosyncratic drug-induced liver injury: A short review. Hepatol Commun. 2017 Jun;1(6):494-500.

12 van Milligen de Wit AW, van Deventer SJ, Tytgat GN. Immunogenetic aspects of primary sclerosing cholangitis: implications for therapeutic strategies. Am J Gastroenterol. 1995 Jun;90(6):893-900.

13 Underhill J, Donaldson P, Bray G, Doherty D, Portmann B, Williams R. Susceptibility to primary biliary cirrhosis is associated with the HLA-DR8-DQB1*0402 haplotype. Hepatology. 1992 Dec;16(6):1404-8. 
14 Gregory WL, Mehal W, Dunn AN, Cavanagh G, Chapman R, Fleming KA, et al. Primary biliary cirrhosis: contribution of HLA class II allele DR8. Q J Med. 1993 Jun;86(6):393-9.

15 Qin B, Wang J, Chen J, Liang Y, Yang Z, Zhong R. Association of human leukocyte antigen class II with susceptibility to primary biliary cirrhosis: a systematic review and meta-analysis. PLoS One. 2013 Nov;8(11):e79580. 


\section{Case Reports in Oncology}

a

INivolumab

TLiver biopsy

V V V Methylprednisolone1g/day

AST Y-GTP

ALT ALP

3201600

2801400

2401200

2001000

$\supset 160800$

120600

80400

40200

$0 \quad 0$

Oda et al.: Cytokine Release Syndrome after Nivolumab

(c) 2019 The Author(s). Published by S. Karger AG, Basel www.karger.com/cro

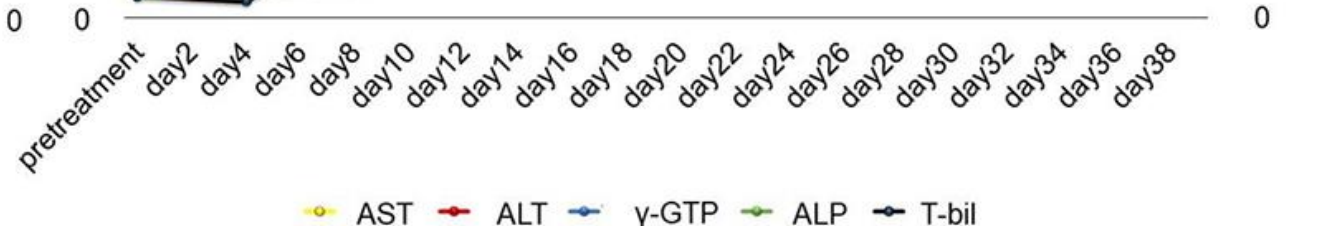

b

Nivolumab

TLiver biopsy

I V Methylprednisolone1g/day

Mycophenolic acid $2000 \mathrm{mg} /$ day

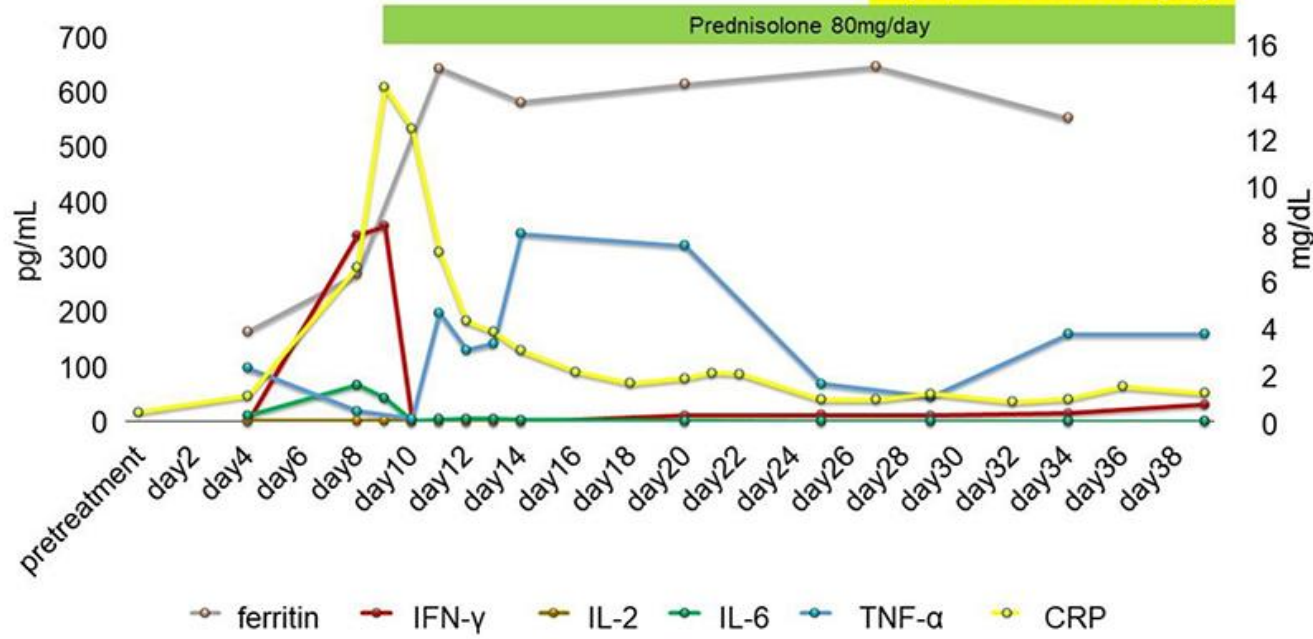

Fig. 1. Course after nivolumab treatment. a) Laboratory data regarding liver function and b) cytokine levels assessed by ELISAs. 


\section{Case Reports in Oncology}

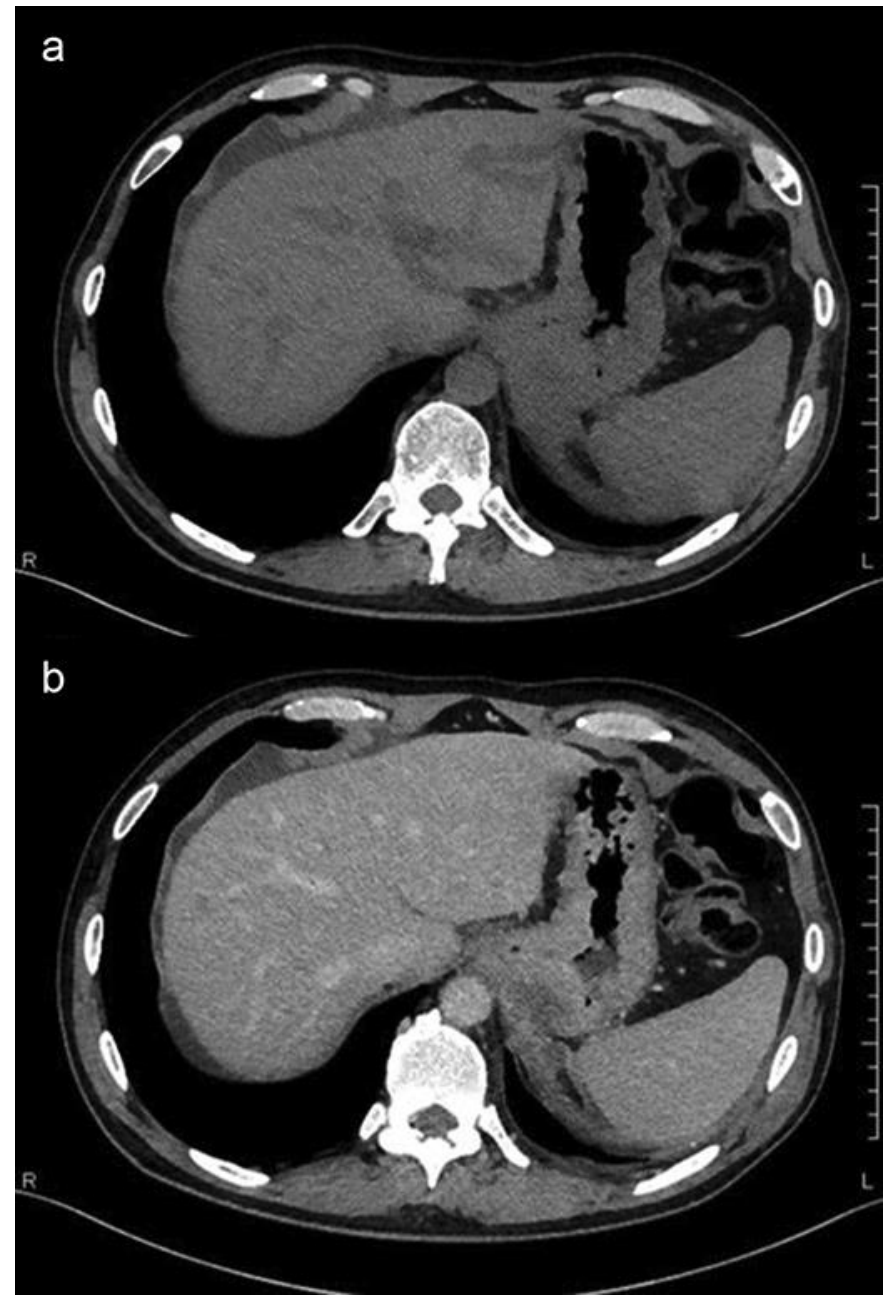

Fig. 2. Computed tomography scans of the liver on day 8. a) Non-contrast computed tomography revealed oedema of the Gleason sheath. b) Contrast computed tomography revealed neither bile duct obstruction nor liver metastasis progression. 


\section{Case Reports in Oncology}
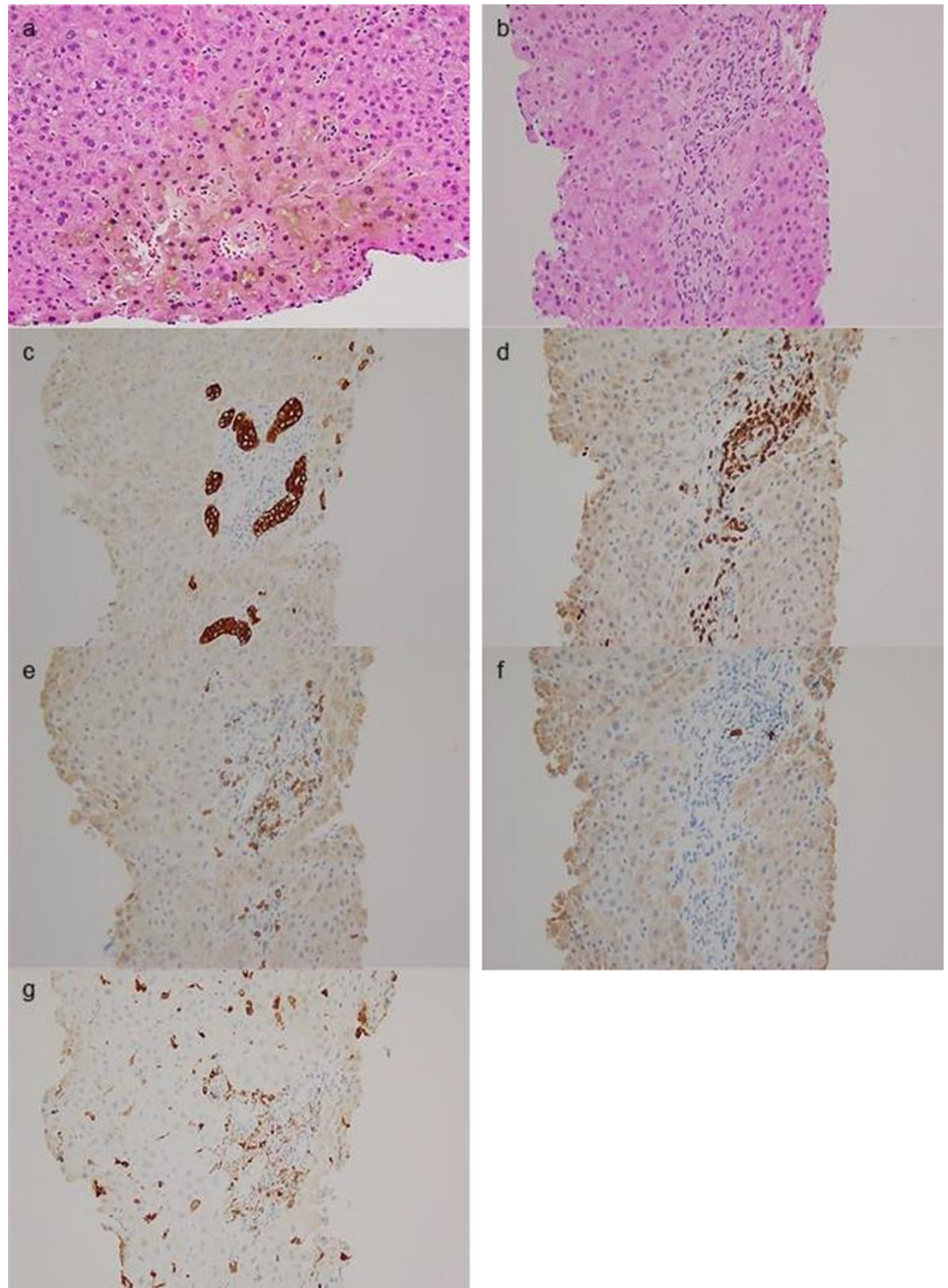

Fig. 3. H\&E staining (a, b) and immunohistochemical examination ( $\mathbf{c}-\mathbf{g})$ of the liver. $\mathbf{c}$ ) Cytokeratin 7 (clone OV-TL 12/30, DAK0); d) CD3 (polyclonal antibody, DAK0); e) CD8 (clone C8/144B, DAKO); f) CD20 (clone L26, DAKO); g) CD68 (clone PG-M1, DAKO). Pathological examination revealed cholestatic liver injury and infiltration of CD8-positive T cells and macrophages into the bile duct. 


\section{Case Reports in Oncology}

Table 1. Laboratory data

\begin{tabular}{|c|c|c|c|}
\hline & Pretreatment & $\begin{array}{l}\text { At the onset of } \\
\text { liver injury and } \\
\text { cholangitis }\end{array}$ & \\
\hline WBC & 2,830 & 6,030 & $/ \mu \mathrm{L}$ \\
\hline $\mathrm{RBC}$ & 417 & 452 & $\times 10^{4} / \mu \mathrm{L}$ \\
\hline HGB & 12.3 & 13.3 & $\mathrm{~g} / \mathrm{dL}$ \\
\hline PLT & 10.1 & 10.1 & $\times 104 / \mu \mathrm{L}$ \\
\hline $\mathrm{TP}$ & 6.0 & 6.3 & $\mathrm{~g} / \mathrm{dL}$ \\
\hline Alb & 3.3 & 3.5 & $\mathrm{~g} / \mathrm{dL}$ \\
\hline Bun & 9.6 & 14.7 & $\mathrm{mg} / \mathrm{dL}$ \\
\hline Cre & 0.68 & 0.71 & $\mathrm{mg} / \mathrm{dL}$ \\
\hline UA & 4.3 & 3.2 & $\mathrm{mg} / \mathrm{dL}$ \\
\hline $\mathrm{Na}$ & 140 & 134 & $\mathrm{mEq} / \mathrm{L}$ \\
\hline K & 4.1 & 4.5 & $\mathrm{mEq} / \mathrm{L}$ \\
\hline $\mathrm{Cl}$ & 103 & 98 & $\mathrm{mEq} / \mathrm{L}$ \\
\hline AST & 36 & 49 & $\mathrm{U} / \mathrm{L}$ \\
\hline ALT & 24 & 31 & IU/L \\
\hline LDH & 184 & 236 & IU/L \\
\hline$\gamma$-GTP & 110 & 151 & $\mathrm{U} / \mathrm{L}$ \\
\hline ALP & 322 & 598 & $\mathrm{U} / \mathrm{L}$ \\
\hline T-bil & 0.9 & 3.7 & $\mathrm{mg} / \mathrm{dL}$ \\
\hline CRP & 0.4 & 6.4 & $\mathrm{mg} / \mathrm{dL}$ \\
\hline Anti-HBs & $<0.30$ & & $\mathrm{mIU} / \mathrm{mL}$ \\
\hline Anti-HBc & 0.06 & & $\mathrm{~S} / \mathrm{CO}$ \\
\hline Anti-HCV & 0.08 & & $\mathrm{~S} / \mathrm{CO}$ \\
\hline Anti-nuclear antibody & $<40$ & $<40$ & \\
\hline EBV nuclear antigen & & 40 & \\
\hline EBV viral capsid antigen antibody-IgG & & 80 & \\
\hline EBV viral capsid antigen antibody-IgM & & $<10$ & \\
\hline CMV p65 antigenemia & & negative & \\
\hline IgG & & $1,188.0$ & $\mathrm{mg} / \mathrm{dL}$ \\
\hline $\operatorname{IgG} 4$ & & 90 & $\mathrm{mg} / \mathrm{dL}$ \\
\hline Smooth muscle antibody & & 40 & \\
\hline \multicolumn{4}{|l|}{ Myeloperoxidase-anti-neutrophil } \\
\hline cytoplasmic antibody & & negative & \\
\hline Anti-mitochondrial antibody & & $<20$ & \\
\hline
\end{tabular}

